\title{
Asymptomatic Hepadnaviral Persistence and Its Consequences in the Woodchuck Model of Occult Hepatitis B Virus Infection
}

\author{
Patricia M. Mulrooney-Cousins and Tomasz I. Michalak* \\ Molecular Virology and Hepatology Research Group, Faculty of Medicine, Health Sciences Centre, Memorial University, \\ St. John's, NL, Canada
}

\begin{abstract}
Woodchuck hepatitis virus (WHV) is molecularly and pathogenically closely related to hepatitis B virus (HBV). Both viruses display tropism towards hepatocytes and cells of the immune system and cause similar liver pathology, where acute hepatitis can progress to chronic hepatitis and to hepatocellular carcinoma (HCC). Two forms of occult hepadnaviral persistence were identified in the woodchuck-WHV model: secondary occult infection (SOI) and primary occult infection (POI). SOI occurs after resolution of a serologically apparent infection with hepatitis or after subclinical serologically evident virus exposure. POI is caused by small amounts of virus and progresses without serological infection markers, but the virus genome and its replication are detectable in the immune system and with time in the liver. SOI can be accompanied by minimal hepatitis, while the hallmark of POI is normal liver morphology. Nonetheless, HCC develops in about $20 \%$ of animals with SOI or POI within 3 to 5 years. The virus persists throughout the lifespan in both SOI and POI at serum levels rarely greater than 100 copies $/ \mathrm{mL}$, causes hepatitis and HCC when concentrated and administered to virus-naïve woodchucks. SOI is accompanied by virusspecific $T$ and $B$ cell immune responses, while only virusspecific $T$ cells are detected in POI. SOI coincides with protection against reinfection, while POI does not and hepatitis develops after challenge with liver pathogenic doses $>1000$ virions. Both SOI and POI are associated with virus
\end{abstract}

Keywords: Hepatitis B; Occult hepatitis B virus infection; Woodchuck model of hepatitis B; Woodchuck hepatitis virus; Secondary occult infection; Primary occult infection; Consequences of occult hepadnaviral infection; Hepatocellular carcinoma.

Abbreviations: $\mathrm{AH}$, acute hepatitis; ALT, alanine aminotransferase; anti-HBC, antibodies against HBV core antigen; anti-HBs, antibodies against HBV surface antigen; anti-WHC, antibodies against WHV core antigen; anti-WHs, antibodies against WHV surface antigen; cccDNA, covalently closed circular DNA; $\mathrm{CH}$, chronic hepatitis; ELISA, enzyme-linked immunosorbent assay; HBsAg, HBV surface antigen; HBV, hepatitis B virus; HCC, hepatocellular carcinoma; HCV, hepatitis $\mathrm{C}$ virus; HIV, human immunodeficiency virus; IFN, interferon; IL, interleukin; $\mathrm{NAH}$, nucleic acid hybridization; NAT, nucleic acid testing; OBI, occult HBV infection; PBMC, peripheral blood mononuclear cells; PCR, polymerase chain reaction; POI, primary occult infection; RT, reverse transcription; SIV, simian immunodeficiency virus; SOI, secondary occult infection; TNF, tumor necrosis factor; WHO, World Health Organization; WHsAg, WHV surface antigen; WHV, woodchuck hepatitis virus.

Received: 02 June 2015; Revised: 20 July 2015; Accepted: 21 July 2015

DOI: $10.14218 /$ JCTH.2015.00020.

*Correspondence to: Tomasz I. Michalak, Molecular Virology and Hepatology Research Group, Faculty of Medicine, Health Sciences Centre, Memorial University, St. John's, NL A1B 3V6, Canada. Tel: +1-709-777-7301, Fax: +1-709-777-8279, E-mail: timich@mun.ca
DNA integration into the liver and the immune system genomes. Overall, SOI and POI are two distinct forms of silent hepadnaviral persistence that share common characteristics. Here, we review findings from the woodchuck model and discuss the relevant observations made in human occult $\mathrm{HBV}$ infection (OBI).

(C) 2015 The Second Affiliated Hospital of Chongqing Medical University. Published by XIA \& HE Publishing Ltd. All rights reserved.

\section{Introduction}

Occult hepatitis $B$ virus (OBI) infection is a distinct form of hepatitis $B$ virus (HBV) infection, identified using highly sensitive assays that detect small amounts of the HBV genome and its replicative intermediates. This silent form of HBV carriage is maintained by persistent virus replication progressing at very low levels. OBI is currently defined as the presence of HBV DNA in the absence of identifiable serum HBV surface antigen (HBsAg), as determined using standard clinical laboratory tests. Because of the inherent difficulties in identifying low levels of HBV in clinical situations, mainly due to insufficient sensitivity of the routine assays and the ethical issues related to serial sampling of seemingly healthy individuals, it was apparent that the employment of a relevant animal model would be highly advantageous for research on the properties, forms, and outcomes of OBI. From the early stages of research on OBI, the eastern North American woodchuck (Marmota monax), which is naturally prone to infection with woodchuck hepatitis virus (WHV), a close relative of HBV ${ }^{1,2}$ was applied. ${ }^{3,4}$ This experimental system became an important source of new information on the natural course, pathogenicity, transmissibility, and epidemiological relevance of occult hepadnaviral persistence. This review will summarize findings that were central to the delineation of virological, molecular, and immunological characteristics and to the recognition of long-term pathological consequences of OBI in the woodchuck model. It will also relate and juxtapose the two forms of occult infection identified in WHV-infected woodchucks, i.e. secondary and primary occult infection, SOI and POI, respectively.

\section{The woodchuck model of HBV infection}

WHV was discovered in a colony of woodchucks in the Philadelphia Zoological Garden, where high rates of chronic 
hepatitis and hepatocellular carcinoma (HCC) were noticed. ${ }^{5,6}$ Subsequent studies have shown that WHV is very similar to $\mathrm{HBV}$ in terms of genome size (3308-3323 and 3182-3221 base pairs, respectively), nucleotide sequence (62-70\%), overall genomic organization, replication strategy, the number, length, and functions of the transcribed viral proteins, and organs targeted (i.e. the liver and the immune system). WHV and HBV also share significant antigenic cross-reactivity and the timing of the appearance of viral antigens in the liver and circulation, as well as antibodies against them are similar. There also is strong compatibility in the induction of the innate and the virus-specific (adaptive) humoral and cellular immune responses, and in the progression and outcomes of liver disease where acute hepatitis $(\mathrm{AH})$ can advance to chronic hepatitis $(\mathrm{CH})$ and $\mathrm{HCC}^{5-9}$ Both infections similarly respond to anti-HBV and immunomodulatory agents, and the drug toxicity and pharmacokinetic profiles are compatible in infected woodchucks and humans. ${ }^{10,11}$ For these and other reasons, the woodchuck-WHV infection has been acknowledged as the most appropriate model of HBV infection and HBV-induced liver disease, even surpassing other currently available natural and transgenic animal models. Nonetheless, there are some differences between WHV and HBV and the diseases caused. At the molecular level, the glycosylation pattern of the virus surface (envelope) proteins is different, ${ }^{12}$ and there are slight discrepancies in the activities of individual enhancers and promoters. ${ }^{13}$ Regarding the disease induced by these viruses, the major differences are that progression of $\mathrm{CH}$ to cirrhosis does not occur in woodchucks and that HCC develops at a high (80-90\%) frequency in animals with serum WHV surface antigen (WHsAg)-positive $\mathrm{CH}$, while $\mathrm{HCC}$ occurs at much lower $(\sim 5 \%)$ rates in patients with $\mathrm{CH}$ type $\mathrm{B}$ and cirrhosis. ${ }^{6,14}$

\section{SOI after resolution of acute hepatitis}

Prior to the era of sensitive nucleic acid testing (NAT), cases of persistent HBV infection in the absence of detectable serum HBsAg and transmission of HBV by blood and organ donations from serum $\mathrm{HBsAg}$-negative individuals were only occasionally reported. ${ }^{15-20}$ The availability of NAT for HBV DNA testing, first for research and then in the clinic, increased the frequency of OBI identification. ${ }^{21-23}$ With time, transmission of HBV by blood transfusions and organ transplantation carrying trace amounts of virus was shown. ${ }^{23-26}$ Severe consequences of OBI reactivation have been observed following immunosuppression or administration of cytotoxic drugs, ${ }^{27-31}$ revealing the high clinical relevance of OBI. In this context, the recent World Health Organization (WHO) estimations indicated that up to 2 billion people have evidence of exposure to HBV. ${ }^{32}$

An early study documented the long-term persistence of $\mathrm{HBV}$ in sequential serum and peripheral blood mononuclear cell (PBMC) samples from individuals with spontaneous resolution of acute hepatitis type $B$. In the presence of detectable antibodies to HBsAg (anti-HBs) and HBV core antigen (anti$\mathrm{HBC}$ ), it was shown that HBV DNA was present in both these compartments for up to 70 months after an apparent complete recovery from AH type B. ${ }^{18}$ HBV DNA was detected by nested polymerase chain reaction (PCR) with primers specific for different HBV genes followed by amplicon detection by nucleic acid hybridization (NAH) to recombinant HBV DNA as a probe (PCR-NAH). The sensitivity of this assay was less than 10 genome copies $/ \mathrm{mL}$, also called virus genome equivalents (vge). It was also shown that HBV DNA reactivity cosedimented with HBsAg in sucrose gradients and exhibited buoyant density of intact complete HBV virions or HBV core particles in cesium chloride gradients. ${ }^{18}$ It was inferred that traces of infectious virus may persist in these convalescent and seemingly healthy individuals for years after termination of self-limited $\mathrm{AH}$. These observations initiated a series of studies in the woodchuck-WHV model.

One of the first studies in woodchucks aimed to ascertain whether WHV persisted after recovery from self-limited $\mathrm{AH}$, and if so, what the longevity of virus endurance was and where the reservoirs of virus replication were. It also was imperative to establish whether persisting virus retained infectivity and what the pathological consequences of such residual infection could be. ${ }^{3}$ Detection of WHV DNA and WHV mRNA using WHV-specific PCR/NAH and reverse-transcriptase PCR (RT-PCR/NAH; sensitivity $<10$ copies/mL or $\mu \mathrm{g}$ of total RNA), respectively, uncovered that low levels of virus genome and its transcription persisted for the lifetime in the liver and in cells of the lymphatic system after resolution of experimentally induced $\mathrm{AH}$. During lifelong follow-up, serum WHV DNA levels fluctuated from 10 to $100 \mathrm{vge} / \mathrm{mL}$, with rare transient increases up to $10^{3} \mathrm{vge} / \mathrm{mL}$. The stealth nature of this silent infection is exemplified by time periods when WHV DNA was not detectable in serum but was in the liver and/or PBMC obtained at the time of serum collection. WHV DNA loads in the liver, PBMC, and lymphatic organs (i.e. bone marrow, spleen) were between 0.02 to $200 \mathrm{vge} / 10^{4}$ liver cells and 0.005 to $0.5 \mathrm{vge} / 10^{4}$ lymphoid cells. Importantly, WHV RNA was detected in serial liver biopsy and PBMC samples up to the end of life, indicating protracted virus replication. The ultimate evidence for productive replication and assembly of infectious virions long after recovery from a self-limited episode of $\mathrm{AH}$ was provided by administration of PBMC-derived inocula (either culture supernatant from ex vivo mitogen-stimulated PBMC or viable non-stimulated PBMC) to virus-naïve woodchucks, which caused AH capable of advancing to $\mathrm{CH}$ and $\mathrm{HCC}$ in some animals. ${ }^{3}$ Serological markers of WHV infection (i.e. immunovirological indicators detectable in serum) were also monitored over the lifetime and while WHsAg was consistently negative, antibodies to WHV core antigen (anti-WHc; an equivalent of anti-HBc in HBV infection) coincided with WHV DNA detection after an acute episode of hepatitis. This form of WHV DNA-positive but serum WHsAg-negative and anti-WHc reactive infection that continued indefinitely after resolution of an episode of symptomatic infection was subsequently designated as SOI (Table 1).3,33-35

In addition to molecular detection of WHV, histological examination of serial liver biopsies collected over the lifetime indicated intermittent minimal-to-mild inflammation with periods of normal or nearly normal liver morphology. However, typical HCC, confirmed by histological examination, ultimately developed in some $(\sim 20 \%)$ animals with SOI (Table 1$){ }^{3}$ The results were startling since the data clearly showed that convalescence from a typical episode of $\mathrm{AH}$ does not prevent development of HCC. It was also found that the virus retained in the lymphoid cells after resolution of $\mathrm{AH}$ caused classical, serologically and histologically evident $\mathrm{AH}$ when transmitted to WHV-naïve woodchucks and that this advanced to $\mathrm{CH}$ and $\mathrm{HCC}$ in some animals. ${ }^{3}$ It was concluded that the virus persisting during SOI remained infectious and liver pathogenic and retained its oncogenic potential. Thus, this study not only confirmed the existence of persistent occult hepadnaviral infection but 
Table 1. Characteristics of primary and secondary occult hepadnavirus infection in the woodchuck model of hepatitis B

\begin{tabular}{|c|c|c|}
\hline & $\begin{array}{l}\text { Primary occult infection (POI) } \\
\text { Primary infection with } \\
<10^{3} \text { WHV virions }\end{array}$ & $\begin{array}{l}\text { Secondary occult infection (SOI) } \\
\text { Residual infection continuing after resolution } \\
\text { of hepatitis or subclinical serologically } \\
\text { evident infection }\end{array}$ \\
\hline $\begin{array}{l}\text { Serology: } \\
\text { WHsAg } \\
\text { anti-WHc } \\
\text { anti-WHs }\end{array}$ & $\begin{array}{l}\text { Neg } \\
\text { Neg } \\
\text { Neg }\end{array}$ & $\begin{array}{l}\text { Neg } \\
\text { Pos } \\
\text { Pos or Neg }\end{array}$ \\
\hline $\begin{array}{l}\text { WHV DNA load: } \\
\text { Serum } \\
\text { PBMC } \\
\text { Liver }\end{array}$ & $\begin{array}{l}<10^{2} \mathrm{vge} / \mathrm{mL} \\
<10^{3} \mathrm{vge} / \mu \mathrm{g} \text { DNA } \\
\mathrm{Neg} \rightarrow \text { Pos }\end{array}$ & $\begin{array}{l}<10^{2} \mathrm{vge} / \mathrm{mL} \\
<10^{3} \mathrm{vge} / \mu \mathrm{g} \text { DNA } \\
<10^{3} \mathrm{vge} / \mu \mathrm{g} \text { DNA }\end{array}$ \\
\hline WHV-specific T cell response & Yes & Yes \\
\hline WHV-specific B cell response & No & Yes \\
\hline Longevity of persistence & Lifelong & Lifelong \\
\hline Infectivity/transmissibility & Yes & Yes \\
\hline $\begin{array}{l}\text { Susceptibility to re-infection with } \\
\text { WHV dose }>10^{3} \text { virions }\end{array}$ & Yes & No \\
\hline $\begin{array}{l}\text { Spectrum of organs involved: } \\
\text { Lymphatic system } \\
\text { Liver }\end{array}$ & $\begin{array}{l}\text { Yes } \\
\text { No } \rightarrow \text { Yes with time }\end{array}$ & $\begin{array}{l}\text { Yes } \\
\text { Yes }\end{array}$ \\
\hline Liver histology & Normal & $\begin{array}{l}\text { Intermittent minimal to moderate inflammation } \\
\text { with periods without alterations }\end{array}$ \\
\hline HCC development & $\sim 20 \%$ & $\sim 20 \%$ \\
\hline
\end{tabular}

WHsAg, WHV surface (envelope) antigen; anti-WHc, antibodies to WHV core (nucleocapsid) antigen; anti-WHs, antibody to WHsAg; HCC, hepatocellular carcinoma; pos, positive; neg, negative; vge, virus genome equivalent.

also identified the natural history, possible pathological outcomes (i.e. HCC), and general virological characteristics of SOI. These findings provided a solid groundwork for further studies on virological and immunological properties of OBI, approaches to its diagnosis, and pathogenic relevance.

\section{The presence of anticore antibodies alone} indicates SOI

The common hallmark of an exposure to hepadnavirus is the presence of antibodies to hepadnavirus nucleocapsid (core) antigen (except WHV POI, see below and Table 1). In the case of WHV, the presence of anti-WHc in the absence of detectable serum WHsAg is a lifelong consequence of recovery from a self-limited episode of hepatitis, as summarized above. Regarding HBV infection, anti-HBc alone can be encountered in a window before the appearance of serum anti-HBs, after resolution of hepatitis $B$, or following a serologically silent (i.e. serum HBsAg-negative) exposure to HBV. However, the virological significance of this finding in regard to virus replication status and virus persistence was uncertain. ${ }^{16,36-38}$ To investigate these issues, two groups of woodchucks were selected from animals injected intravenously (i.v.) with $10^{10}$ DNasedigestion-protected WHV virions of the same or very closely related inoculum. One group $(n=6)$ developed primary serum WHsAg-negative infection not detectable by a sensitive enzyme-linked immunosorbent assay (ELISA), while the other group $(n=7)$ developed a transient episode of typical, serum WHsAg-positive $\mathrm{AH}^{39}$ The origin of this divergent pattern was unclear but was most likely related to host milieu than to the virus itself, since the same inoculum caused both infection outcomes. In this regard, a swift and more effective innate response, a lower susceptibility of some animals to WHV infection, or a masking of low levels of circulating WHsAg by anti-WHs could be possible underlying factors. The woodchucks were followed for 11 to 64 months after virus inoculation. ${ }^{39}$ The results indicated that the detection of anti-WHc in the absence of WHsAg was concomitant with the detection of WHV DNA in the serum, liver, and PBMC. Moreover, serial liver biopsies and PBMC collected during the WHsAg-nonreactive period in both groups demonstrated WHV replication intermediates, i.e. covalently closed circular DNA (cccDNA) and mRNA. In addition, electron microscopy on ultracentrifugated anti-WHc-positive sera from woodchucks, which were serum WHsAg-negative by ELISA, revealed singular 22 to $24 \mathrm{~nm}$ spherical and short tubular WHsAg particles. These findings demonstrated that the persistence of anti-WHc in the absence of conventionally detectable WHsAg in serum is an excellent surrogate indicator of ongoing low-level WHV infection. These findings were in line with other evaluations that demonstrated that the WHV residing within lymphoid cells of woodchucks with the anti-WHc alone profile was infectious to WHV-naïve animals. ${ }^{3,39}$ Occult WHV infection persisting after a self-limiting episode of $\mathrm{AH}$ was also accompanied by $\mathrm{T}$ lymphocyte responses directed to different WHV antigenic epitopes that endure for very long time, if not for life (unpublished data). ${ }^{40}$ This type of persistent $T$ cell reactivity also existed in individuals with a past history of self-limited AH type B. ${ }^{34,41-43}$ 
Mulrooney-Cousins P.M. et al: Woodchuck model of OBI

Transmission of WHV from mothers with SOI to their offspring

The existence of lifelong SOI raised the question whether virus persisting in this form of infection is transmissible from mothers to the litter. Woodchuck offspring born to dams, who resolved experimentally induced $\mathrm{AH}$, developed antibodies to WHV surface antigen (anti-WHs) and established SOI, were followed for up to 3.5 years after birth and investigated for molecular, serological, and histological evidence of WHV infection. ${ }^{4}$ The data showed that all offspring $(n=11)$ examined remained serum WHsAg and anti-WHc nonreactive as well as anti-WHs negative. However, all of them carried trace amounts of WHV DNA in sera and PBMC throughout the entire observation period. Importantly, WHV cccDNA and mRNA, indicative of active replication, were detected in PBMC and in organs of the immune system. The ability of immune cells to produce infectious WHV was confirmed by i.v. injection of culture supernatants from cells stimulated with a mitogen (lipopolysaccharide) to virus-naïve woodchucks. The injected animals developed typical serum WHsAg-reactive $\mathrm{AH}^{4}$

However, serial liver biopsies obtained from some $(n=4)$ of the offspring were, surprisingly, completely WHV negative, despite extensive testing by highly sensitive PCR/NAH assays with primers specific for different virus genes. ${ }^{4}$ Thus, in these animals, the virus was solely expressed and actively replicating, albeit at very low levels, in the PBMC and cells in the lymphatic organs. In another case, liver biopsies collected for up to 19 months after birth were WHV DNA negative, but subsequent biopsies were WHV DNA and cccDNA reactive. In the remaining animals $(n=6)$, all liver biopsies collected from 6 months after birth until the end of follow-up were WHV DNA positive. Histological examination showed normal hepatic tissue morphology in all offspring, except in those that were challenged with WHV doses known to be large enough to cause hepatitis (see below). The persistence of intact virions in the offspring studied, including those with liver WHV-negative infection, was confirmed by testing the physicochemical properties of circulating WHV DNA-reactive particles, with DNase digestion-protection assay, and by infection of virus-naive woodchucks with pools of serum and plasma from the offspring after their concentration by ultracentrifugation.

The above findings clearly showed that hepadnavirus was transmitted from mothers with SOI to their newborns, even though the mothers carried otherwise protective anti-WHs. The study also discovered the existence of a molecularly evident, serologically negative (i.e. WHsAg and anti-WHc nonreactive) persistent WHV infection. The data showed that WHV can exclusively persist in the cells of the immune system without engaging the liver, suggesting that the virus at low doses is preferentially, if not exclusively, lymphotropic. This also demonstrated the truly stealth nature of hepadnaviral infection, as the initiation of the liver infection can occur months or even years after the initial exposure to virus. This finding was recently confirmed in a study on the characteristics and long-term pathological consequences of POI (see below). ${ }^{44}$

Moreover, the low levels of persistent WHV in these offspring was not able to induce a protective immune response. ${ }^{4}$ Thus, when three of the offspring were challenged with a large dose of WHV (also called, liver pathogenic dose; see below), they became serum WHsAg and anti-WHc positive and developed classical $\mathrm{AH}$. This was clearly distinct from animals with
SOI, which were protected against such challenge. This form of occult infection was later designated as POI (Table 1).

\section{POI is caused by very small amounts of WHV}

Interestingly, WHV in the offspring born to dams with SOI was solely confined to the lymphatic system in about $40 \%$ of offspring. This intriguing fact initiated a series of experiments to determine how this may happen and to develop a reproducible model for future investigations. Two approaches were used to study the nature of viral requirements that lead to the establishment of POI. The first was directed at revealing whether or not naturally acquired neonatal POI limited to the lymphatic system can be transferred to adult, immunocompetent woodchucks and, if so, whether the infection retained its molecular and serological characteristics through the passage. The second approach focused on establishing POI in adult woodchucks using a wild-type WHV as inoculum and examined how POI affects the host's susceptibility to and/or recovery from challenge with a dose of WHV that was large enough to cause hepatitis.

\section{Serial passage of POI established after vertical transmission}

Serum samples collected from an offspring that acquired POI from a mother with SOI were pooled and concentrated by ultracentrifugation, and the resulting pellet was i.v. injected into two healthy, adult woodchucks. ${ }^{34}$ From one of these two woodchucks, the pellet recovered from concentrated plasma and isolated splenocytes were then separately i.v. administered to two other healthy adult animals. ${ }^{34}$ All four of these animals developed serologically silent (i.e. serum WHsAg and anti-WHc negative) but WHV DNA positive infection that was restricted to the lymphatic system. However, approximately 5 months after inoculation, low levels of WHV DNA was evident in the liver of two of the animals. ${ }^{34}$ In one case, liver histology showed minimal lymphomononuclear cell infiltrations and moderate proliferation of bile ducts, signifying marginal inflammation. WHV ccCDNA was detected in the spleen and bone marrow, albeit at low levels, confirming virus replication within the immune system. Partial sequence analysis of WHV DNA isolated from the spleen and bone marrow of the woodchuck that received splenocytes from an animal infected with serum from the offspring with neonatal POI did not identify any unique mutations. Thus, the sequence analyzed was identical to that of WHV used to infect the mother of the offspring. ${ }^{34}$ Furthermore, WHV challenge of the adult animals with POI with a large dose $\left(\sim 10^{10}\right.$ virions $)$ of the same virus that was used to inoculate the mother caused typical, serum WHsAg-positive, self-limited $\mathrm{AH}$, indicating again that POI did not provide immune protection against WHV. Thus, this finding was identical to that identified in offspring born to mothers with SOI. ${ }^{4}$ These results unequivocally proved that POI is an experimentally demonstrable entity that can be serially transmitted between immunocompetent hosts. Moreover, they confirmed that the virus persisting during POI maintained its molecular and virological properties and displayed preferable tropism towards cells of the immune system. 


\section{POI is initiated by WHV doses smaller than 1000 virions}

To further characterize the viral requirements initiating POI, WHV-naïve, adult woodchucks were i.v. injected with titrated doses of WHV ranging from 10 to $10^{7}$ DNase-digestionprotected virions that carried wild-type WHV DNA, as confirmed by sequencing. ${ }^{34}$ The results showed that WHV doses equal to or less than $10^{3}$ virions induced POI, while those greater than $10^{3}$ virions caused serum WHsAg-positive infection coinciding with hepatitis. It was also noticed that WHV at amounts of $10^{3}$ virions can cause either POI or serologically evident infection and $\mathrm{AH}$, suggesting that the outcome of infection at this particular virus dose was host dependent. ${ }^{34}$

As previously shown, WHV replication was restricted to the cells of the lymphatic system in animals that developed POI, as confirmed by detection of WHV cccDNA in the bone marrow, isolated splenocytes, and PBMC. ${ }^{34}$ Moreover, the WHV DNA sequences within the splenocytes and plasma in animals with POI were identical to that of the initial inoculum, indicating that the dose of the virus but not the existence of viral variants was responsible for the induction of POI. Similar to the woodchucks that developed POI after a naturally acquired neonatal infection, animals with experimentally induced POI were not protected from challenge with a large, liver pathogenic WHV dose, and they developed serum WHsAg-positive AH. Taken as a whole, this study identified virological requirements responsible for the commencement of POI. WHV quantities below or above $10^{3}$ virions were found to be pivotal in determining whether POI or serologically overt infection followed by SOI was induced, respectively. Liver nonpathogenic doses consistently caused, at least initially, infection of the immune system. These findings were confirmed by using inocula derived from different animals with serum WHsAg-positive $\mathrm{CH}$ when low amounts of WHV (i.e. $<10^{3}$ virions) were i.v. injected. ${ }^{44-46}$ Because of the considerable similarities between WHV and HBV, including the capability of HBV to infect the immune system, ${ }^{16,47-49}$ these data justify the further investigation of infections caused by trace amounts of HBV in humans. Nonetheless, it should be noted that our findings in woodchucks with POI were in contrast to subsequent data indicating that one virion of HBV derived from an HBV transgenic mouse was able to cause serologically detectable chronic hepatitis in a chimpanzee. ${ }^{50}$ Differences in the liver pathogenic potency between a single $\mathrm{HBV}$ isolate from a transgenic mice and authentic, intact WHV might explain this discrepancy.

\section{Repeated exposure to small amounts of WHV does not culminate in hepatitis}

We aimed to determine if multiple small amounts of WHV causing POI could be additive over time and result in serologically evident infection coinciding with hepatitis. To test this possibility, WHV-naïve, adult woodchucks were i.v. injected 12 times with a dose of 100 virions over two rounds of six injections given at weekly intervals. ${ }^{46}$ Approximately 3 months after the last injection, the woodchucks were challenged with a liver pathogenic dose $\left(1.1 \times 10^{10}\right.$ virions) of the same WHV inoculum and followed for an additional 6 months. Detailed examination of serological and molecular markers of WHV infection, histology of serial liver biopsies, and WHV-specific and generalized (mitogeninduced) $\mathrm{T}$ cell responses were performed. The results showed that multiple exposures did not result in serologically detectable infection (i.e. WHsAg and anti-WHc positive) or hepatitis, even though the cumulative dose was above the threshold known to induce WHV hepatitis (i.e. $>10^{3}$ virions). Nonetheless, the infection was accompanied by clearly identifiable WHV-specific T cell response that occurred, characteristically, in the absence of anti-WHc or anti-WHs antibodies, i.e. virus-specific $B$ cell response. ${ }^{40,45,46}$ As expected, the woodchucks were not protected against challenge with a liver pathogenic WHV dose. It was concluded that the WHVspecific $T$ cell response is a very sensitive indicator of occult hepadnaviral persistence, even when this response occurred in the absence of anti-WHc. A similar finding was reported for humans. ${ }^{43}$

As indicated, the disparity between the presence of hepadnavirus-specific T cell reactivity and antivirus antibodies was associated with the lack of protection against infection with liver-pathogenic doses of WHV (i.e. $>10^{3}$ virions). This finding is consistent with data from studies on other asymptomatic viral infections, such as hepatitis $\mathrm{C}$ virus (HCV), simian immunodeficiency virus (SIV), and human immunodeficiency virus type 1 (HIV). ${ }^{51-56}$

Repeated contacts with small amounts of HBV may occur in both occupational and familial settings, such as close contacts of infected individuals, primary healthcare and social service providers, and in i.v. drug users. ${ }^{18,22,23,36,41}$ The results from woodchucks summarized above suggest that trace amounts of HBV that infect unvaccinated individuals will unlikely cause serologically detectable infection (i.e. HBsAg and/or anti-HBc positive) or clinically evident hepatitis $B$ but may lead to the establishment of POI and the development of HBV-specific T lymphocyte responses.

\section{Pathological significance of lifelong WHV POI}

The liver pathogenic relevance of hepadnaviral infection enduring as POI was investigated in a prospective study of woodchucks inoculated with WHV doses known to cause POI. These animals were followed throughout their natural lifespan or until they were challenged with a liver pathogenic dose of WHV. Thus, POI was induced by i.v. injection with 10 or 100 virions from two different WHV inocula. ${ }^{44}$ As expected, all woodchucks $(n=10)$ developed POI restricted to the lymphatic system. ${ }^{44}$ Serum WHV DNA loads detected throughout the life of these animals were usually between $<100$ and $200 \mathrm{vge} / \mathrm{mL}$, and the levels in PBMC were $<10^{3} \mathrm{vge} / \mu \mathrm{g}$ of cellular DNA. It was also found that after 2.5 to 3.3 years of infection, WHV DNA, mRNA, and/or ccCDNA became detectable in the liver of these animals. Although the virus finally engaged the liver, liver histology remained normal throughout follow-up thereafter. ${ }^{44}$ The engagement of the liver was preceded by a temporal increase in serum WHV load to $>1 \times 10^{3}$ $\mathrm{vge} / \mathrm{mL}$. As previously documented, this threshold defines whether occult or overt WHV infection will develop. ${ }^{9,34}$

The most notable finding of the study was that $20 \%$ of the woodchucks with POI developed multinodular HCC, as confirmed by histological examination. HCC developed 55 months after injection of 100 virions. Thus, the study documented that the virus persisting during POI maintained its oncogenic potential, and this highlighted the pathological importance of this seemingly innocuous form of hepadnaviral infection. In this context, it has been shown that seronegative, HBV DNA-reactive infection occurs in HBV endemic regions at rates of up to $7.6 \% .^{57,58}$ This rate is most likely 
underestimated due to infrequent testing for HBV DNA in asymptomatic individuals and the relatively low sensitivity of the commonly used HBV DNA detection assays. The results from the above study in woodchucks suggest that the role of HBV POI in the pathogenesis of HCC of unknown etiology should be considered and investigated.

Another one of our noteworthy findings was the demonstration of the infectivity and liver pathogenic properties of virus that persisted during POI. Hence, WHV retrieved after ultracentrifugation of pools of serum and plasma samples collected from either the liver WHV-negative or the liver WHV-positive phases of POI was i.v. injected to healthy woodchucks $(n=5) .{ }^{44}$ All animals established serum WHsAg-positive, anti-WHc-reactive infection with minimal to moderate hepatitis. Interestingly, three of the woodchucks developed HCC within 4.5 to 35 months post-infection, and two of the animals were injected with virus recovered from the liver WHV-negative phase of POI. In addition, when WHV DNA sequences identified in the liver virus-negative or the liver virus-positive phases of POI were compared to each other and to the sequence of WHV in inoculum used for induction of POI in these animals, the predicted amino acid sequences were essentially identical, indicating that a cell type-specific variant was not likely responsible for the initiation of the liver virus-positive phase of POI. Furthermore, WHV sequences from the liver-virus negative POI phase retained the same sequence in serum and liver when injected to healthy animals, but unique nonsynonymous variants were detected within PBMC. This may imply that WHV propagated more robustly in the immune cells than in the liver in this situation. Overall, the results revealed that WHV, regardless of whether it was retrieved from the liver WHV-negative or the liver WHV-positive phase of POI, initiated infection involving both the liver and the lymphatic system. This confirmed that the virus tropism to hepatocytes and immune cells is a natural property of the authentic, wild-type virus and not a consequence of a virus variant uniquely predisposed to infect a particular cell type. This result is in accordance with the in vitro infection study where WHV was subjected to serial passage in either woodchuck hepatocytes or lymphoid cells without the development of cell type-specific virus variants or changing virus in vivo infectivity. ${ }^{59}$

\section{Occult infection coincides with WHV DNA integration into the host genome}

Random integrations of HBV DNA into the liver genome have been well documented in advanced chronic hepatitis $B$ and related HCC. ${ }^{60,61} \mathrm{HBV}$ genome integrations were also identified in the PBMC of patients with chronic hepatitis B. ${ }^{49}$ In contrast, HBV DNA integrations in OBI have been rarely examined. However, there is some evidence that HBV DNA integrates into $\mathrm{HCC}$ and non $\mathrm{HCC}$ liver DNA in $\mathrm{HBsAg}$-negative patients regardless of anti-HBc detection. ${ }^{60-65}$

WHV DNA insertions have been found in HCC caused by WHV during either $\mathrm{CH}$ or SOI. ${ }^{14,66}$ In WHV-induced $\mathrm{CH}$, virushost junctions have been most often detected near myc prooncogenes. ${ }^{67-69}$ In regard to WHV POI, we recently identified multiple WHV DNA-host genome junctions in the liver and lymphatic organs, including bone marrow, spleen, and lymph nodes, using inverse-PCR designed to specifically detect WHV $X$ gene or WHV pres region integrations. ${ }^{44}$ WHV-host genome junctions were found whether HCC had developed or not and were most often between the WHV
$X$ gene and various host sequences. ${ }^{44}$ This is consistent with the tendency of the HBV $X$ gene to preferably integrate into the human genome. ${ }^{63,70,71}$ To date, the integration sites identified in woodchucks with POI-associated HCC have not been located in the proximity of the myc oncogene sequence.

The immune system is an unvarying site of WHV infection

The role of the immune system as the reservoir and site of active WHV replication during both symptomatic and occult infections has been clearly shown through studies in the woodchuck model. In addition to highly sensitive, PCR/ $\mathrm{NAH}$-based techniques for the detection and quantification of WHV DNA, mRNA, and ccCDNA, in situ PCR coupled with flow cytometric identification of cells carrying amplified WHV genome signals can be used to efficiently amplify WHV DNA within intact lymphoid cells. ${ }^{72}$ This technique allows for the enumeration of WHV DNA-reactive cells. To ensure that the virus DNA was truly located within the cells, DNase-trypsin-DNase treatment to strip the cell surfaces of any potentially attached virions or virus DNA was performed prior to testing by in situ PCR. The results showed that a significant proportion of the lymphoid cells were WHV DNA reactive in serum $\mathrm{WHsAg-positive} \mathrm{AH}$ or $\mathrm{CH}(3.4 \%$ to $20.4 \%$, mean $9.6 \%$ ). Interestingly, PBMC collected during SOI and POI were WHV DNA-reactive at a similar frequency, ranging from $1.1 \%$ to $14.6 \%$, (mean $4.4 \%$ ). ${ }^{72}$ Thus, even though there were differences in terms of serological markers of SOI and POI, there was no difference in the average number of lymphoid cells carrying the virus. This was accompanied by comparable loads of WHV DNA in PBMC from SOI and POI (Table 1). ${ }^{33-35,39,40,73-75}$

\section{Immune responses in occult WHV infections}

\section{Virus-specific $T$ and $B$ cell responses}

WHV-specific $T$ lymphocyte and antibody responses and profiles of cytokine expression in circulating lymphoid cells and serial liver biopsies were studied in both SOI and POI, including the time periods after challenge with liver pathogenic ( $>10^{3}$ virions) or nonpathogenic ( $<10^{3}$ virions) doses of WHV. ${ }^{33,34,40,45,46,73}$ Since SOI is accompanied by antiWHc and frequently by anti-WHs, this indicates that the WHV-specific B cell response remains operational in this form of WHV infection. WHV-specific T cells found during SOI also retained their ability to respond to WHV and its antigens, ${ }^{40}$ similar to individuals with a past episode of selflimited AH type $B{ }^{36,41,43}$ The WHV-specific T cell reactivity in SOI is directed against multiple virus epitopes and remains detectable for years after resolution of $\mathrm{AH}$, although it tends to wane over time. Interestingly, WHV-specific T cell responses, which generally arise at approximately 6 weeks post-infection, are preceded by an enhanced capacity of $T$ lymphocytes to proliferate when exposed to nonspecific mitogens. This heightened state of lymphocyte activation occurs immediately after infection and has been shown to coincide with activation-induced apoptotic death of lymphocytes. ${ }^{73}$ This generalized activation and lymphocyte death most likely contribute to a delay in the initiation of WHVspecific $T$ cell response at the time when this response is critical for a swift elimination of invading virus. ${ }^{40,45,46}$ 
With respect to POI, surprisingly, the profiles of virusspecific and generalized (mitogen-induced) T cell proliferative responses to the initial and subsequent exposures to WHV were the same as those identified in animals infected with liver pathogenic doses or in those with SOI. ${ }^{40,45,46}$ However, unlike SOI, neither anti-WHc nor anti-WHs were detected during POI, suggesting that infection with very small amounts of virus was insufficient to stimulate and maintain memory B cell response.

\section{Cytokine expression in occult WHV infection}

Immediately after exposure to either liver pathogenic or liver nonpathogenic doses of WHV, peripheral lymphocytes displayed a heightened proliferative response to nonspecific mitogens (i.e. generalized $T$ cell response) and exhibited similar profiles of enhanced expression of interferon (IFN)- $\alpha$, interleukin (IL)-12, and IL-2. 40,45,46 Notably, the kinetics of the cytokine responses in circulating lymphoid cells in POI were undistinguishable from those seen during infection caused by liver pathogenic doses of WHV. ${ }^{40,45,46}$

Transcription of cytokines and immune cell marker genes was also quantified in serial liver biopsies collected during POI and after challenge of the animals with POI with a liver pathogenic or a liver nonpathogenic dose of WHV. ${ }^{40,45,46}$ In general, the results showed that despite the absence of detectable WHV in the liver during POI, the liver transcription of IFN- $\alpha$ was upregulated, while that of tumor necrosis factor (TNF) $-\alpha$, IFN- $\gamma$, IL-4, or CD3 was unaltered.

\section{Reactivation of occult WHV infection}

The clinical relevance of the residual hepadnaviral persistence became even clearer with experiments in woodchucks with SOI that were treated with immunosuppressive agents, such as cyclosporin $\mathrm{A}(\mathrm{CsA})^{76}$ and dexamethasone (DEX) (Mulrooney-Cousins et al., unpublished data). It was shown that after even short periods of immunosuppression, reappearance of serum WHsAg-positive infection ensued. In one study, woodchucks that seemingly had completely resolved neonatal WHV infection (i.e. cleared detectable serum WHsAg and WHV DNA and developed anti-WHs by 6 months of age) were followed for up to 6.5 years after birth and treated i.p. with CsA once daily for 12 weeks. ${ }^{76}$ Following treatment, WHV DNA loads in the serum rose to $\sim 1 \times 10^{5}$ to $1 \times 10^{9} \mathrm{vge} / \mathrm{mL}$ by 4 to 6 weeks after the initiation of treatment in $75 \%$ of the animals tested. Also, serum WHsAg became detectable, and the antigen remained positive for about 4 months. An increase in serum levels of alanine aminotransferase (ALT) and sorbitol dehydrogenase (SDH) above normal values was evident in $25 \%$ of the woodchucks, indicating a transient liver injury. ${ }^{3}$ A study with DEX was performed in woodchucks with SOI lasting for 2-3 years after resolution of experimental $\mathrm{AH}$. Thus, these animals were consistently serum WHV DNA-positive at low levels (10-100 vge/mL), WHsAg-negative, and anti$\mathrm{WHc}$ reactive. They were treated with $2 \mathrm{mg} / \mathrm{kg}$ of DEX daily by i.p. injections for 10 days. Serum WHV DNA loads in the treated animals increased up to $2.9 \times 10^{5} \mathrm{vge} / \mathrm{mL}$ early after treatment initiation. The liver samples collected immediately after the termination of treatment showed a 3-fold increase in WHV DNA load. A brief reappearance of serum WHsAg as well as a transient increase in serum SDH indicative of liver injury were also noticed (Mulrooney-Cousins et al., unpublished data). Taken together, these data indicated that immunosuppressive agents used even for a short period of time may cause the reactivation of occult infection and re-establish hepatitis.

Several drugs and chemotherapeutic agents have been identified that have the ability to reactivate HBV in those who either spontaneously or due to antiviral treatment apparently completely cleared HBV infection. ${ }^{27-31,77-82}$ Many case reports and retrospective studies have shown that there are a multitude of clinical outcomes from a very mild episode of hepatitis to fulminant hepatitis, liver failure, and death. The molecular mechanisms of reactivation of HBV infection from the pre-existing occult infection are not yet defined. The well characterized woodchuck models of SOI and POI offer a unique opportunity to fully delineate the pathogenesis of $\mathrm{HBV}$ reactivation in OBI, to evaluate whether new chemotherapies and immunosuppressive agents might reactivate OBI, and to determine ways to eradicate HBV persisting at levels not detectable by conventional assays.

\section{Conclusions}

The woodchuck model of hepatitis B has significantly contributed to identification of virological and immunological characteristics of occult HBV infection and its long-term pathological outcomes and to the recognition of the natural history and the basic biological properties of hepadnaviral infection in general. Reproducible experimental systems to study both POI (i.e. a serologically unapparent but molecularly evident, asymptomatic infection caused by traces of infectious virus) and SOI (i.e. a residual asymptomatic infection continuing after resolution of a serologically evident infection) were established in eastern North American woodchucks. In addition, the woodchuck model considerably contributed to the recognition of the pivotal role of the immune system in the persistent maintenance of hepadnaviral replication, even in the absence of the liver involvement, and in the production of infectious and liver pathogenic and oncogenic virus. The expertise gained during studies of the woodchuck-WHV model should serve to advance our understanding of other important aspects of OBI, including the mechanisms underlying its reactivation and the recurrence of potentially life-threatening hepatitis, the modes of clinically unapparent virus transmission, and to test the efficacy of novel approaches aimed at eradication of OBI.

\section{Acknowledgements}

The authors thank the former and current graduate and postdoctoral research trainees and staff of the Molecular Virology and Hepatology Research Group at the Faculty of Medicine, Memorial University of Newfoundland (MUN) for their contributions to the research summarized in this paper. They also thank the former and current staff members of the Animal Care Facility at the Health Science Center, MUN where the Woodchuck Viral Hepatitis Research Facility (WVHRF) is housed.

The studies were supported by operating grants MA-9256, MT-11262, RO-15174 and MOP-14818 from the Canadian Institutes of Health Research (CIHR), formerly the Medical 
Research Council of Canada. T.I.M. is Senior Canada Research Chair in Viral Hepatitis/Immunology supported by the Canada Research Chair Program, CIHR and Canada Foundation for Innovation.

\section{Conflict of interest}

None

\section{Author contributions}

Writing the paper, selection of references, and preparation of the final version of the paper (PMMC, TIM).

\section{References}

[1] Summers J, Smolec JM, Snyder R. A virus similar to human hepatitis B virus associated with hepatitis and hepatoma in woodchucks. Proc Natl Acad Sci USA $1978 ; 75: 4533-4537$.

[2] Werner BG, Smolec JM, Snyder RL, Summers J. Serological relationship of woodchuck hepatitis virus to human hepatitis B virus. J Viro 1979;32: 314-322.

[3] Michalak TI, Pardoe IU, Coffin CS, Churchill ND, Freake DS, Smith P, et al. Occult life-long persistence of infectious hepadnavirus and residual liver inflammation in woodchucks convalescent from acute viral hepatitis. Hepatology 1999;29:928-938. doi: 10.1002/hep.510290329.

[4] Coffin CS, Michalak TI. Persistence of infectious hepadnavirus in the offspring of woodchuck mothers recovered from viral hepatitis. J Clin Invest 1999;104: 203-212.

[5] Summers J, Mason WS. Replication of the genome of a hepatitis B-like virus by reverse transcription of an RNA intermediate. Cell 1982;29:403-415. doi: 10.1016/0092-8674(82)90157-X.

[6] Popper H, Shih JWK, Gerin DC, Wong DC, Hoyer BH, London WT, et al. Woodchuck hepatitis and hepatocellular carcinoma: correlation of histologic with virologic observations. Hepatology 1981;1:91-98.

[7] Michalak TI. The woodchuck animal model of hepatitis B. Viral Hepatitis Rev 1998;4:139-165.

[8] Michalak TI. Occult persistence and lymphotropism of hepadnaviral infection: insights from the woodchuck viral hepatitis model. Immunol Rev 2000;174: 98-111. doi: 10.1034/j.1600-0528.2002.017406.x.

[9] Mulrooney-Cousins PM, Michalak TI. New aspects of natural history and pathogenicity of hepadnaviral infection and hepatocyte function revealed by the woodchuck model of hepatitis B. In: Yoshiaki Mizuguchi, ed. Liver Biopsy in Medicine. Rijeka, Croatia: Intech, 2011:355-378.

[10] Menne S, Cote PJ. The woodchuck as an animal model for pathogenesis and therapy of chronic hepatitis B virus infection. World J Gastroenterol 2007;13: 104-124. doi: 10.3748/wjg.v13.i1.104.

[11] Roggendorf $M$, Yang D, Lu M. The woodchuck: a model for therapeutic vaccination against hepadnaviral infection. Pathologie Biologie 2010;58: 308-314. doi: 10.1016/j.patbio.2010.04.005.

[12] Tolle TK, Glebe D, Linder M, Linder D, Schmitt S, Geyer R, et al. Structure and glycosylation patterns of surface proteins from woodchuck hepatitis virus. J Virol 1998;72:9978-9985.

[13] Di Q, Summers J, Burch JB, Mason WS. Major differences between WHV and HBV in the regulation of transcription. Virology 1997;229:25-35.

[14] Korba BE, Wells FV, Baldwin B, Cote PJ, Tennant BC, Popper $\mathrm{H}$, et al. Hepatocellular carcinoma in woodchuck hepatitis virus infected woodchucks. Presence of viral DNA in tumor tissue from chronic carriers and animals serologically recovered from acute infections. Hepatology 1989;9:461-470.

[15] Hoofnagle JH, Seeff LB, Bales ZB, Zimmerman HJ. Type B hepatitis after transfusion with blood containing antibody to hepatitis $B$ core antigen. N Engl J Med 1978;298:1379-1383. doi: 10.1056/NEJM197806222982502.

[16] Liang TJ, Blum HE, Wands JR. Characterization and biological properties of a hepatitis $B$ virus isolated from a patient without hepatitis $B$ virus serologic markers. Hepatology 1990;12:204-212.

[17] Feray C, Zignego AL, Samuel D, Bismuth A, Reynes M, Tiollais $P$, et al. Persistent hepatitis $B$ virus infection of mononuclear blood cells without concomitant liver infection: the liver transplantation model. Transplantation 1990;49:1155-1158.

[18] Michalak TI, Pasquinelli C, Guilhot S, Chisari FV. Hepatitis B virus persistence after recovery from acute viral hepatitis. J Clin Invest 1994;93:230-239.

[19] Uemoto S, Sugiyama K, Marusawa H, Inomata Y, Asonuma K, Egawa H, et al. Transmission of hepatitis B virus from hepatitis B core antibody-positive donors in living related liver transplantation. Transplantation 1998;65: 494-499.
[20] Mason AL, Xu L, Guo L, Kuhns M, Perrillo RP. Molecular basis for persistent hepatitis $B$ virus infection in the liver after clearance of serum hepatitis $B$ surface antigen. Hepatology 1998;27:1736-1742. doi: 10.1002/hep.510270638.

[21] Bläckberg J, Kidd-Ljunggren K. Occult hepatitis B virus after acute selflimited infection persisting for 30 years without sequence variation. J Hepatol 2000;33:992-997. doi: 10.1016/S0168-8278(00)80134-8.

[22] Hu KQ. Occult hepatitis B virus infection and its clinical implications. J Viral Hepat 2002;9:243-257. doi: 10.1046/j.1365-2893.2002.00344.x.

[23] Raimondo G, Allain JP, Brunetto MR, Buendia MA, Chen D-S, Colombo M, et al. Statements from the Taormina expert meeting on occult hepatitis $B$ virus infection. J Viral Hepat 2008;49:652-657. doi: 10.1016/j.jhep.2008. 07.014.

[24] Gerlich WH, Bremer C, Saniewski M, Schuttler CG, Wend UC, Willems WR, et al. Occult hepatitis $\mathrm{B}$ virus infection: detection and significance. Dig Dis 2010;28:116-125. doi: 10.1159/000282074.

[25] Allain JP, Mihaljevic I, Gonzalez-Fraile MI, Gubbe K, Holm-Harritshøj L, Garcia $\mathrm{JM}$, et al. Infectivity of blood products from donors with occult hepatitis B virus infection. Transfusion 2013;53:1405-1415. doi: 10.1111/trf.12096.

[26] Squadrito G, Spinella R, Raimondo G. The clinical significance of occult HBV infection. Ann Gastroenterol 2014;27:15-19.

[27] Schmeltzer P, Sherman KE. Occult hepatitis B: clinical implications and treatment decisions. Dig Dis Sci 2010;55:3328-3335. doi: 10.1007/s10620010-1413-0.

[28] Shouval D, Shibolet O. Immunosuppression and HBV reactivation. Semin Liver Dis 2013;33:167-177. doi: 10.1055/s-0033-1345722.

[29] Raimondo G, Filomia R, Maimone S. Therapy of occult hepatitis B virus infection and prevention of reactivation. Intervirology 2014;57:189-195. doi: $10.1159 / 000360943$

[30] Kim HY, Kim W. Chemotherapy-related reactivation of hepatitis B infection: updates in 2013. World J Gastroenterol 2014;20:14581-14588. doi: 10.3748 /wjg.v20.i40.14581.

[31] Seto WK. Hepatitis B virus reactivation during immunosuppressive therapy: Appropriate risk stratification. World J Hepatol 2015;7:825-830. doi: 10 . 4254/wjh.v7.i6.825.

[32] www.who.int/mediacentre/factsheets/fs204/en, accessed July 2013.

[33] Hodgson PD, Michalak TI. Augmented hepatic interferon gamma expression and T-cell influx characterize acute hepatitis progressing to recovery and residual lifelong virus persistence in experimental adult woodchuck hepatitis virus infection. Hepatology 2001;34:1049-1059. doi: 10.1053/jhep.2001. 29004.

[34] Michalak TI, Mulrooney PM, Coffin CS. Low doses of hepadnavirus induce infection of the lymphatic system that does not engage the liver. J Virol 2004;78:1730-1738. doi: 10.1128/JVI.78.4.1730-1738.2004.

[35] Michalak TI, Pham TNQ, Mulrooney-Cousins PM. Molecular diagnosis of occult HCV and HBV infections. Future Med 2007;2:451-465.

[36] Rehermann B, Ferrari C, Pasquinelli C, Chisari FV. The hepatitis B virus persists for decades after patients' recovery from acute viral hepatitis despite active maintenance of a cytotoxic T-lymphocyte response. Nat Med 1996;2: 1104-1108.

[37] Yotsuyanagi $\mathrm{H}$, Yasuda $\mathrm{K}$, Iino $\mathrm{S}$, Moriya $\mathrm{K}$, Shintani $\mathrm{Y}$, Fujie $\mathrm{H}$, et al. Persistent viremia after recovery from self-limited acute hepatitis $B$. Hepatology 1998;27:1377-1382. doi: 10.1002/hep.510270526.

[38] Murakami Y, Minami M, Daimon Y, Okanoue T. Hepatitis B virus DNA in liver serum, and peripheral blood mononuclear cells after the clearance of serum hepatitis B surface antigen. J Med Virol 2004;72:203-214. doi: 10.1002/ jmv.10547.

[39] Coffin CS, Pham TNQ, Mulrooney PM, Churchill ND, Michalak TI. Persistence of isolated antibodies to woodchuck hepatitis virus core antigen is indicative of occult virus infection. Hepatology 2004;40:1053-1061. doi: 10.1002/ hep. 20419.

[40] Gujar SA, Jenkins AK, Guy CS, Wang J, Michalak TI. Aberrant lymphocyte activation preceded delayed virus-specific $T$ cell response after both primary infection and secondary exposure to hepadnavirus in the woodchuck model of hepatitis B infection. J Virol 2008;82:6992-7008. doi: 10.1128/JVI. 00661-08.

[41] Penna A, Artini M, Cavalli A, Levero M, Bertoletti A, Pilli M, et al. Long-lasting memory T cell responses following self-limited acute hepatitis B. J Clin Invest 1996;98:1185-1194. doi: 10.1172/JCI118902.

[42] Bes M, Vargas V, Piron M, Casamitjana N, Esteban JI, Vilanova N, et al. T cell responses and viral variability in blood donation candidates with occult hepatitis B infection. J Hepatol 2012;56:765-774. doi: 10.1016/j.jhep. 2011.11.011.

[43] Zerbini A, Pilli M, Boni C, Fisicaro P, Penna A, Di Vincenzo $P$, et al. The characteristics of the cell-mediated immune response identify different profiles of occult hepatitis B virus infection. Gastroenterology 2008;134:1470-1481. doi: $10.1053 /$ j.gastro.2008.02.017.

[44] Mulrooney-Cousins PM, Chauhan R, Churchill ND, Michalak TI. Primary seronegative but molecularly evident hepadnaviral infection engages liver and induces hepatocellular carcinoma in the woodchuck model of hepatitis $B$. PLoS Pathog 2014;10:e1004332. doi: 10.1371/journal.ppat.1004332. 
[45] Gujar SA, Michalak TI. Primary occult hepadnavirus infection induces virusspecific T-cell and aberrant cytokine responses in the absence of antiviral antibody reactivity in the woodchuck model of hepatitis $B$ virus infection. J Virol 2009;83:3861-3876. doi: 10.1128/JVI.02521-08.

[46] Gujar SA, Mulrooney-Cousins PM, Michalak TI. Repeated exposure to trace amounts of woodchuck hepadnavirus induces molecularly evident infection and virus-specific $T$ cell response in the absence of serological infection markers and hepatitis. J Virol 2013;87:1035-1048. doi: 10.1128/JVI. 01363-12.

[47] Mason A, Yoffe B, Noonan C, Mearns M, Campbell C, Kelley A, et al. Hepatitis $B$ virus DNA in peripheral-blood mononuclear cells in chronic hepatitis $B$ after HBsAg clearance. Hepatology 1992;16:26-41.

[48] Stoll-Becker S, Repp R, Glebe D, Schaefer S, Kreuder J, Kann M, et al. Transcription of hepatitis $B$ virus in peripheral blood mononuclear cells from persistently infected patients. J Virol 1997;71:5399-5407.

[49] Laskus T, Radkowski M, Wang LF, Nowicki M, Rakela J. Detection and sequence analysis of hepatitis $B$ virus integration in peripheral blood mononuclear cells. J Virol 1999;73:1235-1238.

[50] Asabe S, Wieland SF, Chattopadhyay PK, Roederer M, Engle RE, Purcell RH et al. The size of the viral inoculum contributes to the outcome of hepatitis $B$ virus infection. J Virol 2009;83:9652-9662. doi: 10.1128/JVI.00867-09.

[51] Koziel MJ, Wong DK, Dudley D, Houghton M, Walker BD. Hepatitis C virusspecific cytolytic $T$ lymphocyte and $T$ helper cell responses in seronegative persons. J Infect Dis 1997;176:859-866.

[52] Kamal SM, Amin A, Madwar M, Graham CS, He Q, Al Tawil A, et al. Cellular immune responses in seronegative sexual contacts of acute hepatitis $C$ patients. J Virol 2004;78:12252-12258. doi: 10.1128/JVI.78.22.1225212258.2004.

[53] Quiroga JA, Llorente S, Castillo I, Rodríguez-Iñigo E, Pardo M, Carreño V. Cellular immune responses associated with occult hepatitis $C$ virus infection of the liver. J Virol 2006;80:10972-10979. doi: 10.1128/JVI.00852-06.

[54] Ochsenbein AF, Pinschewer DD, Odermatt B, Ciurea A, Hengartner $H_{\text {, }}$ Zinkernagel RM. Correlation of $\mathrm{T}$ cell independence of antibody responses with antigen dose reaching secondary lymphoid organs: implications for splenectomized patients and vaccine design. J Immunol 2000;164: 6296-6302. doi: 10.4049/jimmunol.164.12.6296.

[55] Promadej N, Costello C, Wernett MM, Kulkarni PS, Robison VA, Nelson KE, et al. Broad human immunodeficiency virus (HIV)-specific $T$ cell responses to conserved HIV proteins in HIV-seronegative women highly exposed to a single HIV-infected partner. J Infect Dis 2003;187:1053-1063. doi: 10.1086/ 368127.

[56] Tasca S, Tsai L, Trunova N, Gettie A, Saifuddin M, Bohm R, et al. Induction of potent local cellular immunity with low dose X4 SHIV(SF33A) vaginal exposure. Virology 2007;367:196-211. doi: 10.1016/j.virol.2007.05.021.

[57] Wong DKH, Huang FY, Lai CL, Poon RTP, Seto WK, Fung J, et al. Occult hepatitis $B$ infection and HBV replicative activity in patients with cryptogenic cause of hepatocellular carcinoma. Hepatology 2011;54:829-836. doi: 10.1002/hep.24551.

[58] Song EY, Yun YM, Park MH, Seo DH. Prevalence of occult hepatitis B virus infection in a general adult population in Korea. Intervirology 2009;52: 57-62. doi: 10.1159/000214633.

[59] Mulrooney-Cousins PM, Michalak TI. Repeated passage of wild-type woodchuck hepatitis virus in lymphoid cells does not generate cell type-specific variants or alter virus infectivity. J Virol 2008;82:7540-7550. doi: 10.1128/ JVI.00405-08.

[60] Bréchot C, Hadchouel M, Scotto J, Fonck M, Potet F, Vyas GN, et al. State of hepatitis $B$ virus DNA in hepatocytes of patients with hepatitis B surface antigen-positive and -negative liver diseases. Proc Natl Acad Sci USA 1981;78:3906-3910.

[61] Farazi PA, DePinho RA. Hepatocellular carcinoma pathogenesis: from genes to environment. Nat Rev Cancer 2006;6:674-687. doi: 10.1038/nrc1934.

[62] Pollicino T, Squandrito G, Cerenzi G, Cacciola I, Raffa G, Crax A, et al. Hepatitis $B$ virus maintains its pro-oncogenic properties in the case of occult HBV infection. Gastroenterology 2004;126:102-110. doi: 10.1053/ j.gastro.2003.10.048.

[63] Higashi Y, Tada S, Miyase S, Hirota K, Imamura H, Kamio T, et al. Correlation of clinical characteristics with detection of hepatitis $B$ virus $X$ gene in liver tissue in HBsAg-negative, and HCV-negative hepatocellular carcinoma patients. Liver 2002;22:374-379. doi: 10.1034/j.1600-0676.2002.01645.x.
[64] Chen L, Zhao H, Yang X, Gao JY, Chen J. HBsAg-negative hepatitis B virus infection and hepatocellular carcinoma. Discov Med 2014;18:189-193.

[65] Saitta C, Tripodi G, Barbera A, Bertuccio A, Smedile A, Ciancio A, et al. Hepatitis $B$ virus (HBV) DNA integration in patients with occult HBV infection and hepatocellular carcinoma. Liver Int 2015. doi: 10.1111/liv.12807.

[66] Hansen LJ, Tennant BC, Seeger C, Ganem D. Differential activation of myc gene family members in hepatic carcinogenesis by closely related hepatitis $B$ viruses. Mol Cell Biol 1993;13:659-667. doi: 10.1128/MCB.13.1.659.

[67] Fourel G, Trepo C, Bougueleret L, Henglein B, Ponzetto A, Tiollais P, et al. Frequent activation of $\mathrm{N}$-myc genes by hepadnavirus insertion in woodchuck liver tumours. Nature 1990;347:294-298. doi: 10.1038/347294a0.

[68] Bruni R, D'Ugo E, Villano U, Fourel G, Buendia MA, Rapicetta M. The win locus involved in activation of the distal $\mathrm{N}-\mathrm{myc} 2$ gene upon WHV integration in woodchuck liver tumors harbors S/MAR elements. Virology 2004;329: 1-10. doi: 10.1016/j.virol.2004.08.008.

[69] Jacob JR, Sterczer A, Toshkov IA, Yeager AE, Korba BE, Cote PJ, et al. Integration of woodchuck hepatitis and $\mathrm{N}$-myc rearrangement determine size and histologic grade of hepatic tumors. Hepatology 2004;39:1008-1016. doi: 10.1002/hep.20106.

[70] Zhang X, You X, Li N, Zhang W, Gagos S, Wang Q, et al. Involvement of hepatitis $B$ virus $X$ gene $(\mathrm{HBX})$ integration in hepatocarcinogenesis via a recombination of $\mathrm{HBx} / \mathrm{Alu}$ core sequence/subtelomeric DNA. FEBS Let 2012;586:3215-3221. doi: 10.1016/j.febslet.2012.06.039.

[71] Toyoda H, Kumada T, Kaneoka Y, Murakami Y. Impact of hepatitis B virus (HBV) $X$ gene integration in liver tissue on hepatocellular carcinoma development in serologically HBV-negative chronic hepatitis C patients. J Hepatol 2008;48:43-50. doi: 10.1016/j.jhep.2007.08.016.

[72] Mulrooney PM, Michalak TI. Quantitative detection of hepadnavirus-infected lymphoid cells by in situ PCR combined with flow cytometry: implications for the study of occult virus persistence. J Virol 2003;77:970-979. doi: 10.1128/ JVI.77.2.970-979.2003.

[73] Gujar SA, Jenkins AKM, MacParland SA, Michalak TI. Pre-acute hepadnaviral infection is associated with activation-induced apoptotic death of lymphocytes in the woodchuck (Marmota monax) model of hepatitis B. Dev Comp Immunol 2010;34:999-1008. doi: 10.1016/j.dci.2010.05.001.

[74] Wang J, Gujar SA, Cova L, Michalak TI. Biscistronic woodchuck hepatitis virus core and gamma interferon DNA vaccine can protect from hepatitis but does not elicit sterilizing antiviral immunity. J Virol 2007;81:903-916. doi: 10.1128/JVI.01537-06.

[75] Pardoe IU, Michalak TI. Detection of hepatitis B and woodchuck hepatitis viral DNA in plasma and mononuclear cells from heparinized blood by the polymerase chain reaction. J Virol Methods 1995;51:227-288.

[76] Menne S, Cote PJ, Butler SD, Toshkov IA, Gerin JL, Tennant BC. Immunosuppression reactivates viral replication long after resolution of woodchuck hepatitis virus infection. Hepatology 2007;45:614-622. doi: 10.1002/hep. 21558.

[77] Torres HA, Davila M. Reactivation of hepatitis B virus and hepatitis C virus in patients with cancer. Nat Rev Clin Oncol 2012;9:156-166. doi: 10.1038/ nrclinonc.2012.1.

[78] Raimondo G, Filomia R, Maimone S. Therapy of occult hepatitis B virus infection and prevention of reactivation. Intervirology 2014;57:189-195. doi: $10.1159 / 000360943$.

[79] Bayliss ], Nguyen T, Lesmana CR, Bowden S, Revill P. Advances in the molecular diagnosis of hepatitis $B$ infection: providing insight into the next generation of disease. Semin Liver Dis 2013;33:113-121. doi: 10.1055/ s-0033-1345714.

[80] Pattullo V. Hepatitis B reactivation in the setting of chemotherapy and immunosuppression - prevention is better than cure. World J Hepatol 2015;7:954-967. doi: 10.4254/wjh.v7.i7.954

[81] López-Serrano P, de la Fuente Briongos E, Alonso EC, Pérez-Calle JL, Rodríguez CF. Hepatitis B and immunosuppressive therapies for chronic inflammatory diseases: When and how to apply prophylaxis, with a special focus on corticosteroid therapy. World J Hepatol 2015;7:539-547. doi: 10.4254/wjh. v7.i3.539.

[82] Mozessohn L, Chan KK, Feld J], Hicks LK. Hepatitis B reactivation in HBsAgnegative/HBcAb-positive patients receiving rituximab for lymphoma: a meta-analysis. J Viral Hepat 2015. doi: 10.1111/jvh.12402. 